\title{
Os Objetos ativos \\ de Willys de Castro ${ }^{1}$
}

\author{
RENATO RODRIGUES DA SILVA
}

$\mathrm{E}$ M 1959, Willys de Castro (1926-1988) iniciou os Objetos ativos. Esses trabalhos resumem as descobertas realizadas desde que colocara em questionamento os pressupostos do Concretismo, passando a freqüentar o ambiente de vanguarda do Rio de Janeiro. Ciceroneado por Ferreira Gullar, o artista entrou em contato com os agentes neoconcretos, tomando conhecimento da obra de Lygia Clark, o que lhe causou profundo impacto. Esse período foi bastante fecundo, pois antigas concepções foram abandonadas em proveito de uma maior liberdade de experimentação. Se a série Soma entre planos criou várias possibilidades de pesquisa, os novos objetos sinalizam um momento de síntese, evidenciando a compreensão que fazia da arte do seu tempo - compreensão essa que, indo além do abstracionismo, incluía a pintura e a escultura em suas características essenciais.

Objeto ativo de 1959 é o primeiro trabalho da série. Ele foi exposto durante a II Exposição Neoconcreta realizada no Ministério da Educação, Rio de Janeiro, em novembro de $1960 .^{2}$ O objeto tem a forma de um retângulo perfeito que apresenta a superfície frontal pintada em amarelo. Mas a declaração do formato não disfarça o preciosismo técnico: Willys de Castro pintou com tinta a óleo uma tela desemoldurada, para, depois, colá-la sobre um chassi de madeira. Apesar da espessura reduzida desse chassi, sua presença física mostrar-se-á fundamental. Por ora, ressaltamos que Objeto ativo de 1959 parece funcionar como uma pintura monocromática. A disposição horizontal e a ausência de centro fazem que o olhar vasculhe a superfície procurando ancorar o ato perceptivo. Trata-se de um esforço inútil: a observação repetida só encontra justificativa em elementos que delimitam o campo pictórico e cuja existência reitera a vacuidade dessas tentativas (Figura 1). ${ }^{3}$

Esses elementos assumem uma importância decisiva, embora esse fato contrarie a insignificância das suas dimensões. Eis que uma linha azul, com a mesma espessura do suporte, atravessa verticalmente o lado direito do trabalho, margeando o campo visual. Willys de Castro deu-lhe um tratamento uniforme, mas deixou sem pintura uma seção intermediária, desvelando a superfície amarela subjacente. A descontinuidade, entretanto, é quase imperceptível, uma vez que o olhar - seguindo um dos postulados da Teoria da Gestalt ${ }^{4}$ - tende a completar essa linha, ignorando a alteração como um mero incidente. Já na extrema esquerda de Objeto ativo de 1959, o artista posicionou outro elemento fundamen- 
tal. Assim, um quadrado azul, com as mesmas dimensões da seção descontínua, mostra-se tão ínfimo que desapareceria caso não tivesse a função de completá-la. Nesse caso, as similaridades de cor e forma estimulam a operação mental de união das partes supostamente separadas.

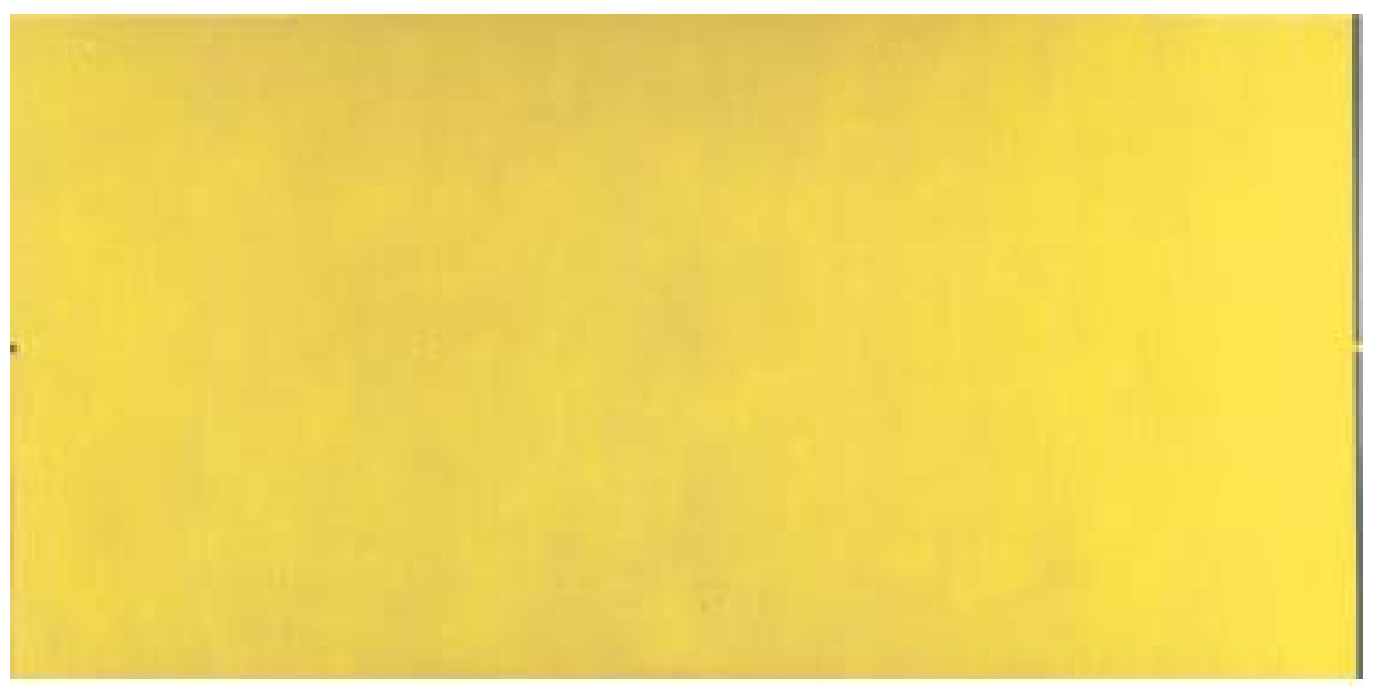

Figura 1 - Objeto ativo de 1959 (2 2 versão) Dimensões: 46,0 X 92,0 X $0,7 \mathrm{~cm}$ Técnica: Óleo sobre tela colada sobre chassi de madeira Coleção: Museu de Arte de São Paulo Assis Chateaubriand (MASP) Fotografia: Luiz Hossaka

Em Objeto ativo de 1959, Willys de Castro empregou um motivo artístico, que denominaremos "positivo-negativo". ${ }^{5} \mathrm{Na}$ pesquisa anterior, seu objetivo era a integração formal dos trabalhos. Em Soma entre planos I, por exemplo, esse motivo é composto pelo recorte de um quadrado do plano superior da pintura; esse quadrado é, depois, deslocado para baixo, adentrando a área púrpura (Figura 2). Tal disposição produz uma maior coesão pictórica ao inter-relacionar elementos que, caso contrário, permaneceriam indiferentes. $\mathrm{O}$ mais importante, contudo, é que o deslocamento cria um espaço negativo, ou uma ausência, que o olhar tenta sucessivamente rejeitar através da reconstrução dos planos originais; essas tentativas provocam uma dinâmica temporal que termina integrando a pintura. Dessa maneira, o artista exibe o resultado de um processo ao mesmo tempo que explicita sua formação.

Naquele momento, Willys de Castro empregou o motivo positivo-negativo numa alternativa, ora centralizando a composição ora estabelecendo núcleos específicos de problematização. ${ }^{6}$ Seja como for, sua utilização recriava supostas unidades, atuando como meio de organização formal. Em Objeto ativo de 1959, porém, ele introduziu uma mudança. Agora, a conexão entre os elementos separados (ou seja, a linha descontínua e o quadrado) não se realiza totalmente, pois 
a experiência visual proporcionada é fraca. Isso ocorre porque as sugestões de união e completude - implícitas à utilização desse motivo - são amenizadas em razão da dimensão reduzida desses elementos e da presença da superfície amarela. Se o olhar tentar reconstruir a forma original, não é a totalidade da linha que

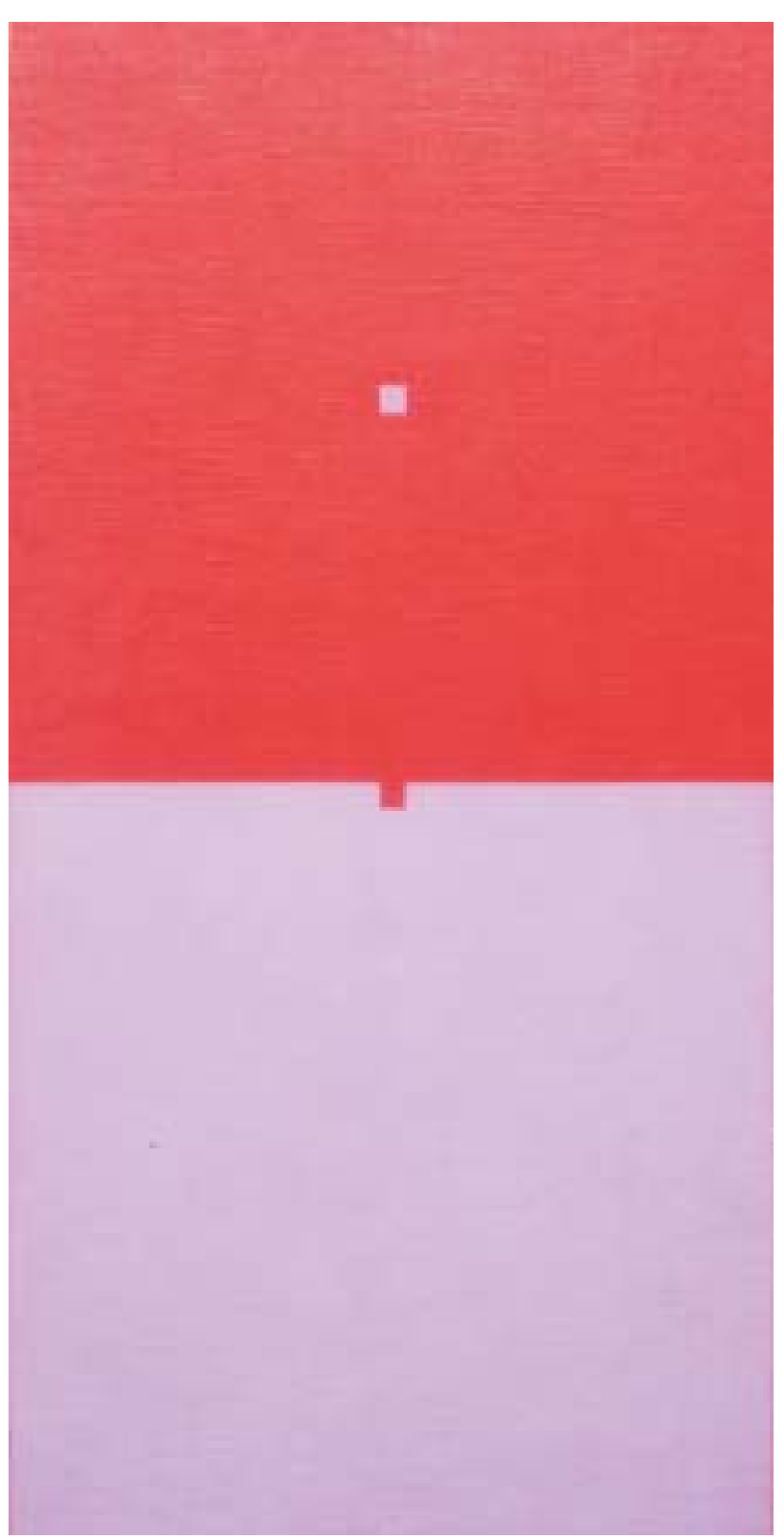

Figura 2 - Soma entre planos I

Ano de realização: 1959

Dimensões: 40,0 X 20,0 cm

Técnica: Óleo sobre madeira

Coleção: Ricardo Akagawa

Fotografia: Mauro Chinen é revelada, mas a decisão do artista. Em conseqüência, a relação que se estabelece é mais conceitual do que perceptiva: o motivo delimita o raio de ação de um gesto consciente. A pintura torna-se o campo ideal dessa operação: entre a experiência e o entendimento, Willys de Castro prioriza a segunda possibilidade.

Desse modo, Willys de Castro introduziu um "signo" em sua pesquisa, transformando os procedimentos pictóricos então usuais. Segundo Ferdinand de Saussure, ele se divide em duas partes, o "significante" e o "significado", que uma vez combinadas produzem uma "forma lingüística". O significante é a "imagem visual" e o significado é o "conceito", e a ligação entre ambos é arbitrária, como também é arbitrária a ligação do signo com seu referente. ${ }^{7}$ Podemos aplicar essa hipótese à nossa análise. Em Objeto ativo de 1959, a imagem visual é dada pela conexão entre a linha segmentada e o quadrado, que juntos integrariam a mesma entidade; mas essa conexão é fraca porque Willys de Castro apresenta também as dimensões reduzidas desses elementos e a superfície frontal como elementos significan- 
tes. Seu gesto consciente fundamenta a utilização paradoxal do motivo positivonegativo. Assim, apontamos as partes constitutivas desse signo: o significante é produzido pela conjugação do motivo e da superfície e o significado é a pintura entendida como uma operação conceitual.

Em última instância, os Objetos ativos destacam-se pela inscrição de signos. Esse procedimento foi raramente utilizado em experiências abstracionistas, que recusaram qualquer forma de simbolização. Indo além da redescoberta de um componente lingüístico na pintura, contudo, seu gesto tornou-se revolucionário. Poucos analistas perceberam a inflexão, mas o estudo detalhado desses trabalhos revela características insuspeitadas. Em Objeto ativo de 1959, Willys de Castro dobrou a tela sobre o suporte, envolvendo as laterais. Não se tratava apenas de um questionamento sobre os limites do objeto, aludindo às convenções que o mantêm apartado do real. Aqui e alhures, o artista desenvolveu uma reflexão sobre os fundamentos da pintura, definindo suas relações com a perspectiva renascentista.

Constatamos também que Willys de Castro multiplicou o motivo positivonegativo, tematizando o suporte. Na direita de Objeto ativo de 1959, a linha azul evidencia que sua condição limítrofe relaciona-se apenas à superfície frontal, porque a lateral é pintada em amarelo. A seção amarela, no entanto, encontra um inesperado prologamento ortogonal, transformando-se num quadrado azul na lateral. Quando o trabalho é visto em diagonal, ele é projetado para cima, de modo a completar aquela linha. Na esquerda, o quadrado azul (que está aparentemente isolado) estende-se num movimento angular de noventa graus, criando uma seção amarela na lateral pintada em azul. Aqui, a visada em diagonal lança o quadrado em profundidade. Os dois motivos atuam de modo simétrico mas invertido - ora privilegiando a superfície frontal ora a lateral -, e em ambos os casos os vértices são ativados. ${ }^{8}$ Desse modo, Willys de Castro integrou criticamente as três dimensões do objeto.

Essas informações sugerem uma nova leitura. A modificação mais importante refere-se ao motivo positivo-negativo. No início, esse signo denotava o "entendimento da pintura como uma operação conceitual". Mas na medida em que o suporte foi incorporado, aquilo que era um conceito tornou-se outra imagem, incentivando a investigação. Agora o significado de Objeto ativo de 1959 define-se como o entendimento da pintura como uma operação conceitual... que se realiza num objeto em três dimensões. Com efeito, a incongruência desse significante - que propõe uma pintura tridimensional, quando esse meio requisita apenas uma superfície plana - envolve conceitos muito diferentes. Talvez seja o momento de enfocarmos a natureza do trabalho, colocando as seguintes perguntas: seria Objeto ativo de 1959 uma pintura ou uma escultura? De que modo Willys de Castro articulou essas categorias?

Essas perguntas serão respondidas adiante. Nesse momento, cabe sublinhar uma das características principais dos Objetos ativos, que operam na estrutu- 
ra da linguagem de modo similar à poesia neoconcreta. ${ }^{9}$ Vimos que o par significante-significado de Objeto ativo de 1959 foi desdobrado. Depois que incorporamos novas informações ao conceito, fomos obrigados a transformá-lo noutra imagem. Nesse patamar discursivo, seríamos levados a reiniciar a pesquisa, identificando outro significado, e assim por diante. É justamente essa abertura na forma lingüística que Willys de Castro explorou em seus objetos. Ele nos deu uma verdadeira lição daquilo que Jacques Derrida denominaria, alguns anos depois, "desconstrutivismo", pois quando o trabalho perde o centro, o significante torna-se superabundante ("overabundance of the signifier"), abrindo o signo ao "jogo" ("play") de múltiplas possibilidades semânticas (cf. Derrida, 1992, p.1117-26).

\section{Da pintura à escultura}

A pesquisa de Willys de Castro durante o período neoconcreto pode ser sintetizada por Objeto ativo de 1960. Considerando-se a clareza, o rigor formal e o resultado, ele representa uma das suas maiores realizações, sendo basicamente composto por um sarrafo de madeira longitudinal, que foi - de acordo com a técnica usual do artista - encoberto por uma tela desemoldurada e, depois, pendurado na parede (Figura 3). A despeito dessa economia, a recepção do trabalho é muito complexa. No Diagrama 1 , analisamos os diferentes sentidos que são produzidos em razão da posição do observador.

\section{Diagrama 1 - Análise da recepção de Objeto ativo de 1960}

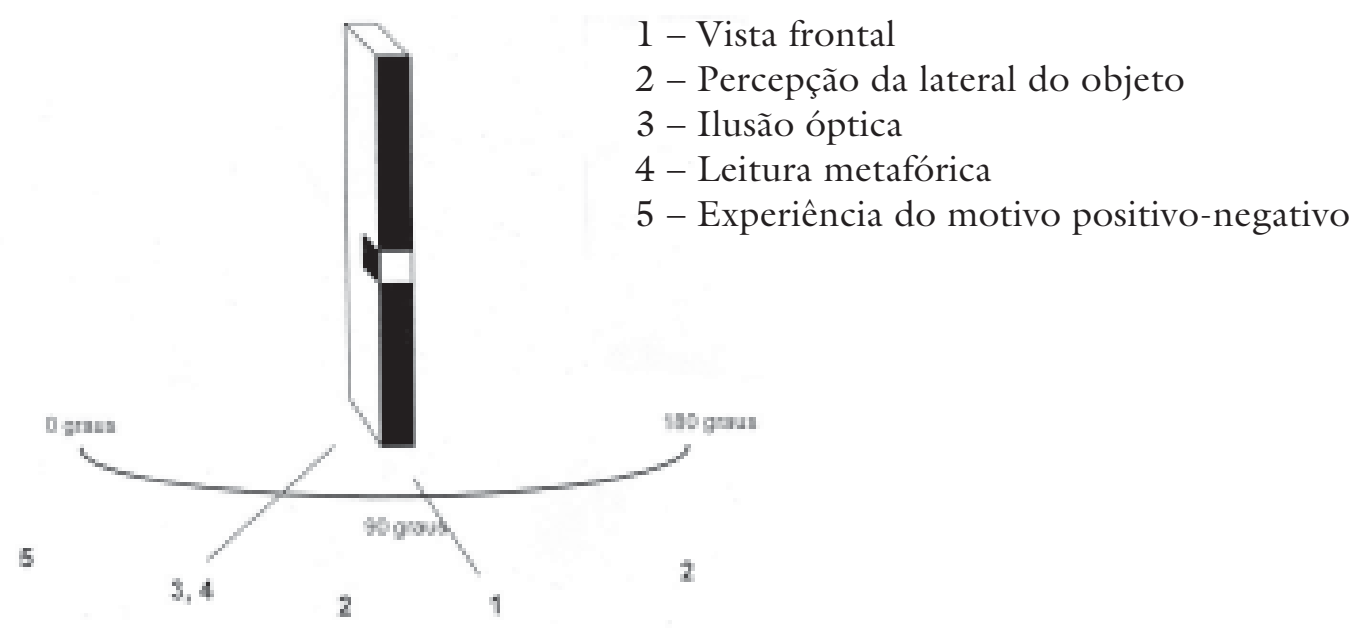

Vista frontal: Em Objeto ativo de 1960, Willys de Castro fez várias alusões à história da arte. A forma de exibição e a superfície frontal (pintada em preto) referendam o antigo espaço pictórico. Assim, o observador depara com um objeto conhecido que lhe demanda um comportamento padrão. A aproximação frontal, não obstante, mostra-se infrutífera: quanto mais o olhar procura o centro, mais ele se frustra. Ademais, a verticalidade exagerada e a ausência de repre- 
sentação favorecem o questionamento. Tal como um "zip" das abstrações de Barnett Newman, o trabalho alonga-se como uma linha de fratura entre campos de cor, desvelando a precariedade do meio, que ainda se faz necessário. ${ }^{10}$ Apesar da referência à pintura, o artista desenvolveu um discurso ambíguo.

Percepção da lateral: Essa referência não impede a percepção do objeto. $\mathrm{O}$ suporte invade o espaço real, explicitando a intromissão de algo que deveria funcionar como o plano de projeção da representação. Mas é através dessa intromissão que Willys de Castro articulou o cálculo rigoroso que preside Objeto ativo de 1960, que requisita a participação do observador. Inadvertidamente, ele abandona a procura do centro, colocando-se em movimento ao descrever uma trajetória semicircular em torno do objeto. Esse movimento esclarece que as laterais são diferentes e contrastam com a superfície frontal. Trata-se de percepções cursivas, sem desdobramentos conceituais imediatos, mas que tornarão patente a complexidade do trabalho. Aquilo que havia começado como pintura transforma-se em escultura - essa transformação é o tema dos Objetos ativos.

Ilusão óptica: As diretrizes visuais de Objeto ativo de 1960, no entanto, interferem nessa experiência. Eis que a parte inferior da superfície frontal exibe uma descontinuidade que decorre da inserção de um pequeno quadrado branco; mesmo que a alteração seja pequena, ela quebra a monocromia. Mediante um deslocamento em negativo, porque o que branco torna-se o contrário, esse quadrado é ortogonalmente transportado para a lateral esquerda. Constatamos a construção do motivo positivo-negativo, contudo, quando o observador colocase numa determinada posição em diagonal, os dois elementos unem-se numa figura imaginária, que era inesperada. Com efeito, essa visada sugere a existência de uma pequena reentrância cúbica na superfície frontal. Agora, o trabalho organiza-se a partir de um efeito visual.

Essa ilusão baseia-se num procedimento conhecido na história da pintura como "anamorfose": "Nesse sistema compósito, a projeção no plano da pintura é sistematicamente distorcida de maneira que ela aparecerá bizarra ou mesmo ilegível quando vista de frente, mas assumirá proporções apropriadas quando vista num ângulo que coloca em perspectiva o próprio plano da pintura" (Kemp, 1990, p.49-50). Um exemplo famoso de anamorfose encontra-se em Os embaixadores (1533), de Hans Holbein: quando nos afastamos do ponto de vista central e observamos essa pintura pela esquerda e por baixo, ela revela uma inscrição insólita, ou seja, uma caveira. Willys de Castro fundamentou a ilusão de Objeto ativo de 1960 nessa técnica: na visão frontal, os dois quadrados mostram-se ilegíveis, mas quando o espectador posiciona-se em diagonal, eles produzem a ilusão de que o objeto fora entalhado. ${ }^{11}$

Em última instância, as variações de sentido dos Objetos ativos resultam da inscrição de signos. Esse é um dos pontos cruciais do nosso artigo. De acordo com os pressupostos da Arte Concreta, entretanto, esses trabalhos deveriam apresentar apenas elementos plásticos puros, desterritorializados. ${ }^{12}$ Em razão da pró- 
pria personalidade, Willys de Castro era avesso às normas, mostrando-se consciente dos caminhos que escolhia. Para analisar Objeto ativo de 1960, portanto, consideramos alguns fatores que escapam a essa tradição, pois sua pesquisa tinha um alcance maior. Esse aspecto tem sido negligenciado, talvez porque não sejamos mais capazes de reconhecer o conteúdo lingüístico dos meios expressivos.

$\mathrm{Na}$ arte moderna, o caso de Willys de Castro

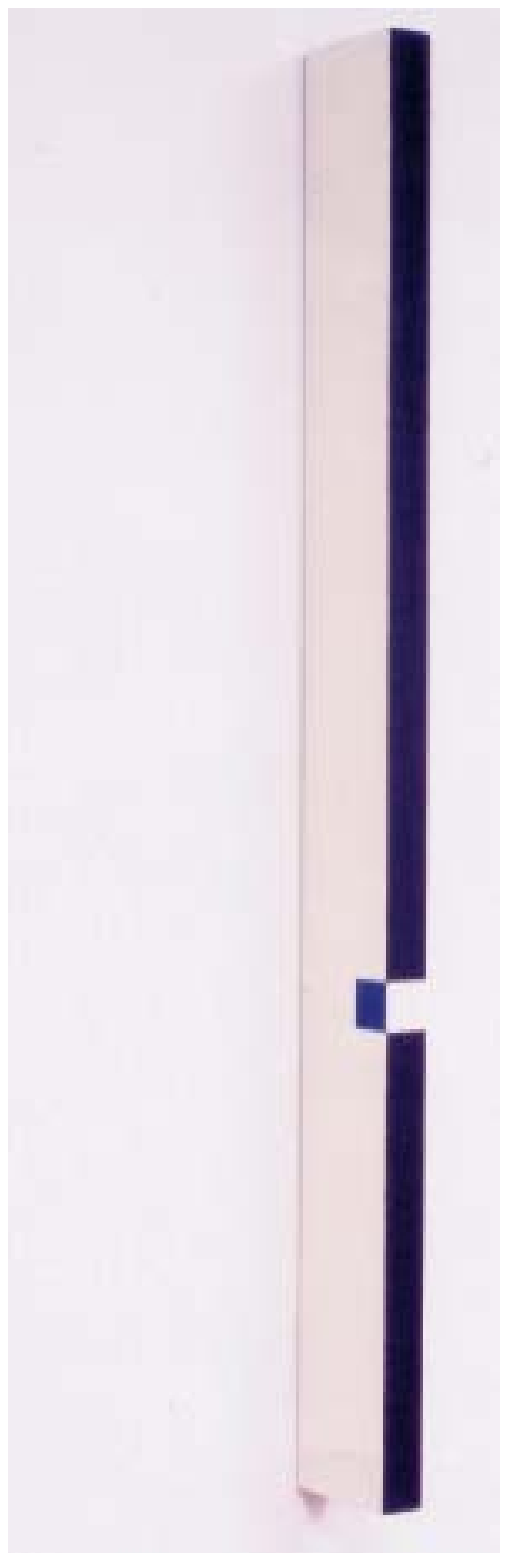

Figura 3 - Objeto ativo de 1960 Dimensões: 68,9 X 2,3 X $6,9 \mathrm{~cm}$ Técnica: Óleo sobre tela colada sobre chassi de madeira Coleção: Adolpho Leirner Fotografia: Mauro Chinen não é único. Picasso inscreveu signos para registrar a sensação de profundidade em várias obras cubistas. Nas colagens, ele imprimiu a letra " $f$ " aos pares com a finalidade de representar os dois orifícios sonoros do tampo de um violino. As dimensões e espessuras contrastantes das letras sugerem a recessão inclinada dessa superfície num espaço ilusório. Como observou Rosalind Krauss (1986, p.33):

Repetidamente, a inscrição envolve uma grande disparidade entre as duas letras, uma sendo maior e freqüentemente mais grossa que a outra. Com essa simples, embora muito enfática, diferença de tamanho, Picasso compõe o signo, não do violino, mas do escorço [foreshortening]: do tamanho diferencial dentro de uma única superfície, devido à sua rotação em profundidade. E porque a inscrição dos $f s$ ocorre dentro da montagem da colagem, e assim sobre os planos mais rigidamente aplainados e frontalizados, a "profundidade" é portanto escrita naquele mesmo lugar onde ela está mais ausente. É essa experiência de inscrição que garante que essas formas tenham o status de signos.

Os procedimentos utilizados pelos dois artistas eram similares, embora visassem objetivos diferentes. ${ }^{13}$ Quando os dois quadrados de Objeto ativo de 1960 são vistos em diagonal, eles inscrevem o signo, não do escorço, mas do entalhe, visto que uma violência é ilusoriamente inferida à integridade do objeto, que aparece escavado.

Como nas colagens, a "profundidade é, portanto, escrita naquele mesmo lugar onde ela está mais ausente", isto é, sobre os planos literalizados do trabalho. Esse fato destaca a segunda diferença de objetivos. Enquanto Picasso empregava a pintura para denunciar suas convenções, Willys de Castro articulou o signo em profundidade, 
produzindo uma ilusão óptica. Seu gesto tornou-se irônico: em Objeto ativo de 1960, os procedimentos da escultura afirmam a pintura. ${ }^{14}$ Nessa leitura, os elementos ganham novas funções: não só o objeto volta a apresentar um apelo visual, sugerindo um registro gráfico, como também os quadrados frontal e lateral apresentam-se, respectivamente, como ausência material (resultado do entalhe virtual) e fundo sombreado, que se coloca paralelo à face do trabalho.

Apesar disso, há um elemento que desempenha uma função construtiva. Trata-se do vértice de Objeto ativo de 1960: mesmo que a perspectiva sugira uma descontinuidade, como se parte dele fosse projetada para o fundo do entalhe, sua vocação é, afinal, reiterada. Segundo um crítico contemporâneo, ele funciona como um verdadeiro "foco da atenção" (Roels, 1988). ${ }^{15}$ Essa avaliação parece-nos acertada: se Willys de Castro queria investigar o diálogo entre a pintura e a escultura, é compreensível que tenha explorado as funções exercidas pelo vértice, que une o plano e o volume, definindo o eixo de construção do espaço tridimensional. É por essa razão que esse elemento é fundamental à constituição do trabalho - que reafirma seu pertencimento ao Construtivismo -, produzindo as significações parciais.

Leitura metafórica: Poderíamos supor que Objeto ativo de 1960 restabelece a pintura como forma dominante? Acreditamos que não, uma vez que o signo implica também uma metáfora da escultura. Essa afirmação merece algumas considerações. Desde o Renascimento - quando o objeto libertou-se da arquitetura, ganhando uma forma autônoma -, essa arte alicerçou-se nos gestos antagônicos de "modelar" e "entalhar" ou "esculpir" a matéria. ${ }^{16}$ Entre os séculos XVI e XIX, contudo, a história criou uma hierarquia, posto que a modelagem foi valorizada; enfim, a experiência do Modernismo, principalmente no século XX, reafirmou o entalhe em razão da ênfase no contato direto com os materiais. Em Objeto ativo de 1960, Willys de Castro reiterou esse paradigma. Mas sua atitude implicava também um julgamento de valor, posto que o entalhe apresenta-se ilusório, resultando de um procedimento visual. Verificamos, portanto, que esse trabalho engendra uma segunda ironia, que decorre do modo como o processo de significação atravessa e reordena os meios expressivos.

Motivo positivo-negativo: Enfim, o observador de Objeto ativo de 1960 dá um passo decisivo em sua trajetória. Esse movimento destrói a ilusão e o quadrado assoma na superfície lateral. Além da metáfora, o signo revela a existência do motivo positivo-negativo. Como vimos, esse motivo baseia-se na suposta união formal e, mesmo que os dois quadrados estejam dispostos em ângulo reto, sua conexão é forte; a dinâmica temporal envolvida no processo tem a função de conectá-los. Willys de Castro reintroduziu a superfície frontal, valorizando a pintura novamente. Ao analisar os Objetos ativos, Ferreira Gullar (1960) descreveu esse momento: "O problema colocado nessas obras é interessante e novo, porque repõe noutros termos o conflito entre a superfície bidimensional e o espaço de profundidade real: o tempo - o movimento do espectador - recupera a bidimensionalidade do espaço tridimensional". ${ }^{17}$ 


\section{Da escultura à pintura}

Antes de concluir os Objetos ativos, Willys de Castro alterou a formulação do problema. Sua intenção era explorar várias combinações possíveis. Na subsérie dos Cubos, desenvolvidos em 1962, ele partiu de um formato tridimensional, escultórico por natureza, para investigar suas interseções com a pintura. ${ }^{18} \mathrm{Um}$ exemplo dessa pesquisa é Objeto ativo de 1962. Trata-se de um cubo de madeira - encoberto por uma tela desemoldurada -, que apresenta a maioria das suas faces pintadas nas cores preto e azul, introduzindo o tema recorrente de um quadrado branco posicionado no canto. A exposição do objeto, no entanto, não nos permite observar a sexta face. Como veremos a seguir, esses quadrados agrupam-se em duas figuras imaginárias, que são os significantes do trabalho.

A declaração inequívoca do formato dificultaria a relativização dos meios expressivos. Assim, Willys de Castro modificou a apresentação de Objeto ativo de 1962, empregando dois procedimentos. Em primeiro lugar, o trabalho foi pendurado para evitar a sobrecodificação da escultura; em razão do translado do chão à parede, uma composição em preto (com um quadrado branco na direita) ganhou destaque. Mas esse posicionamento criou outro problema, visto que o alinhamento horizontal fazia alusão à pintura, sugerindo que o quadro ganhara volume. Para evitar essa leitura, o artista aplicou uma torção de 45 graus ao objeto, colocando-o numa posição diagonal (Figura 4). Assim, a função escultórica foi restabelecida, sem, no entanto, recusar outras leituras.

Quando Objeto ativo de 1962 é visto da direita, os três quadrados adquirem uma dimensão espacial. ${ }^{19}$ Referimo-nos ao cubo branco: embora essa figura seja ilusória, sua presença visual é marcante (Figura 5). A sensação de unidade é reforçada pela diversidade do contexto, pois as faces que o apresentam estão pintadas em preto e azul. Em última instância, porém, essa sensação é provocada pela perspectiva que Willys de Castro criou através do encontro das três arestas, porque o vértice funciona como o "foco da atenção", conectando o observador. O fato de esse ponto ser tangível resulta de uma estratégia que aproveita as características do trabalho para inscrever-lhe um signo - ou melhor, para inscrever-lhe um meta-signo, pois a representação de um cubo é empregada para questionar a forma (cúbica) do objeto. Neste artigo, analisaremos essa representação.

Usando a sucessão de registros semânticos, o artista desconstruiu esse signo duas vezes. Como em Objeto ativo de 1960, as leituras espaciais e visuais sucedem-se: o movimento do espectador ganha significação e a visada em diagonal materializa a figura principal. A aproximação daquele ponto de observação em que as arestas de Objeto ativo de 1962 mostram-se perfeitamente simétricas (projetando um hexágono regular) engendra uma ambigüidade no trabalho, que agora escava um espaço côncavo. Através desse efeito - que é descrito em teoria da percepção ${ }^{20}$-, Willys de Castro produziu uma inversão, que denuncia a arbitrariedade da representação. Podemos formulá-la da seguinte maneira: quando as faces do objeto declaram sua literalidade, o cubo branco apresenta uma 
totalização virtual; não obstante, quando elas recedem ficticiamente, a espacialidade (aberta) dessa figura é revelada. Tal inversão comprova que o artista conhecia o fenômeno óptico, sabendo manipulá-lo em benefício da pesquisa.

Tudo se passa como num laboratório, onde cada gesto é devidamente calculado. Para evitar que a visada em diagonal anulasse outras possibilidades, o artista criou uma leitura complementar. Quando Objeto ativo de 1962 é visto da esquerda, os três quadrados aparecem separados, sugerindo que o cubo branco sofrera um desmembramento a partir do vértice. ${ }^{21}$ Além disso, as faces do objeto que apresentam a figura são pintadas em preto, estabelecendo um fundo (indiferente) para a realização do procedimento. Dessa maneira, a figura proposta na primeira perspectiva é desmontada pela segunda, e o espectador tem a impressão de descobrir os elementos constitutivos do cubo, sendo recompensado pelo esforço analítico (Figura 6). Mas de qual "cubo" estamos falando aqui, da representação ou do objeto? De fato, através do conteúdo metonímico desse signo, acabamos desconstruindo o próprio trabalho, desvelando sua arbitrariedade e seu regime de significação.

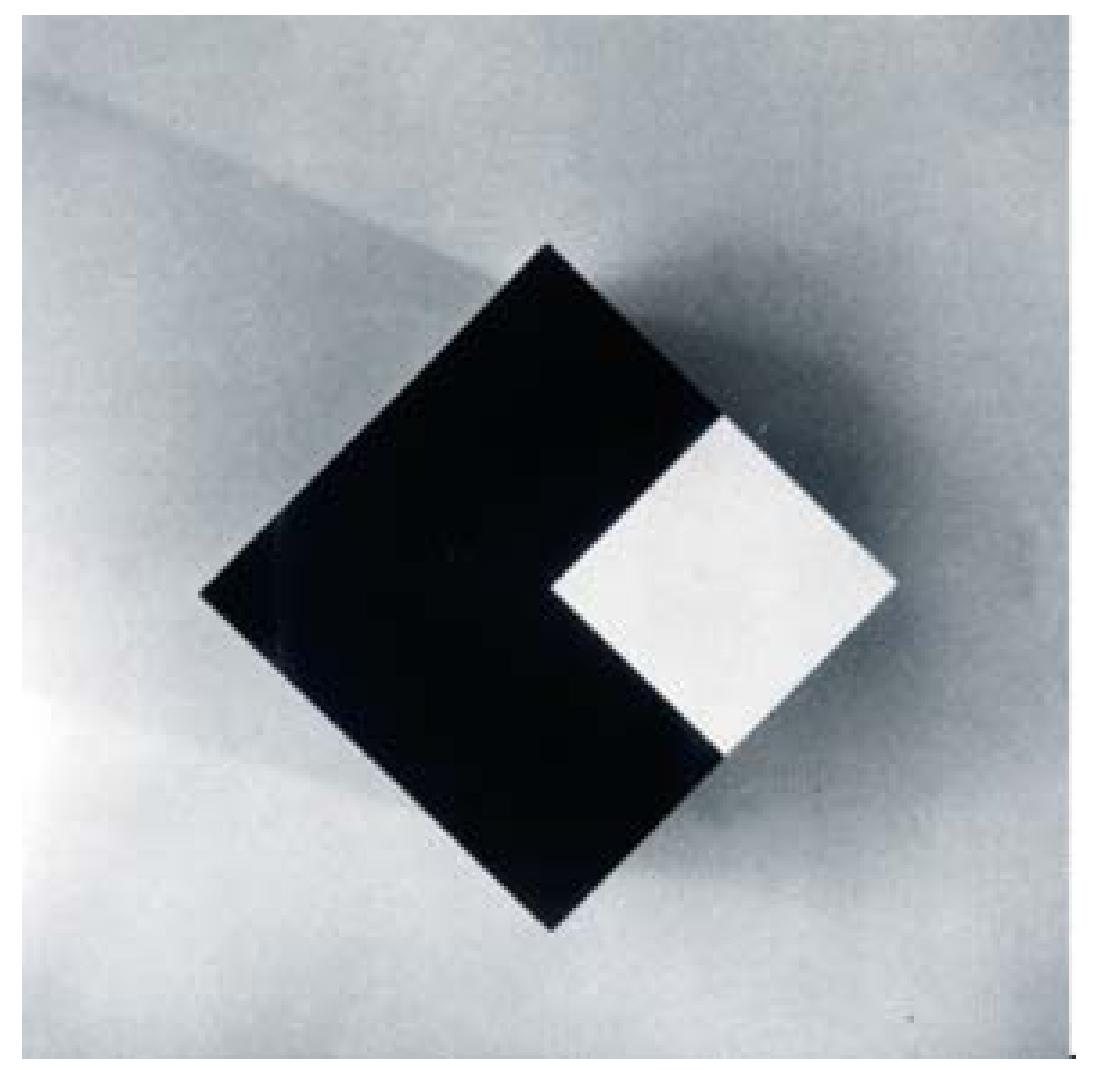

Figura 4 - Objeto ativo de 1962 (vista frontal)

Dimensões: 25,0 X 25,0 X 25,0 cm

Técnica: Óleo sobre tela colada sobre chassi de madeira

Coleção: Pinacoteca do Estado de São Paulo Fotografia: "Arquivo Pluri e Ativo de Willys de Castro" - (IAC) 


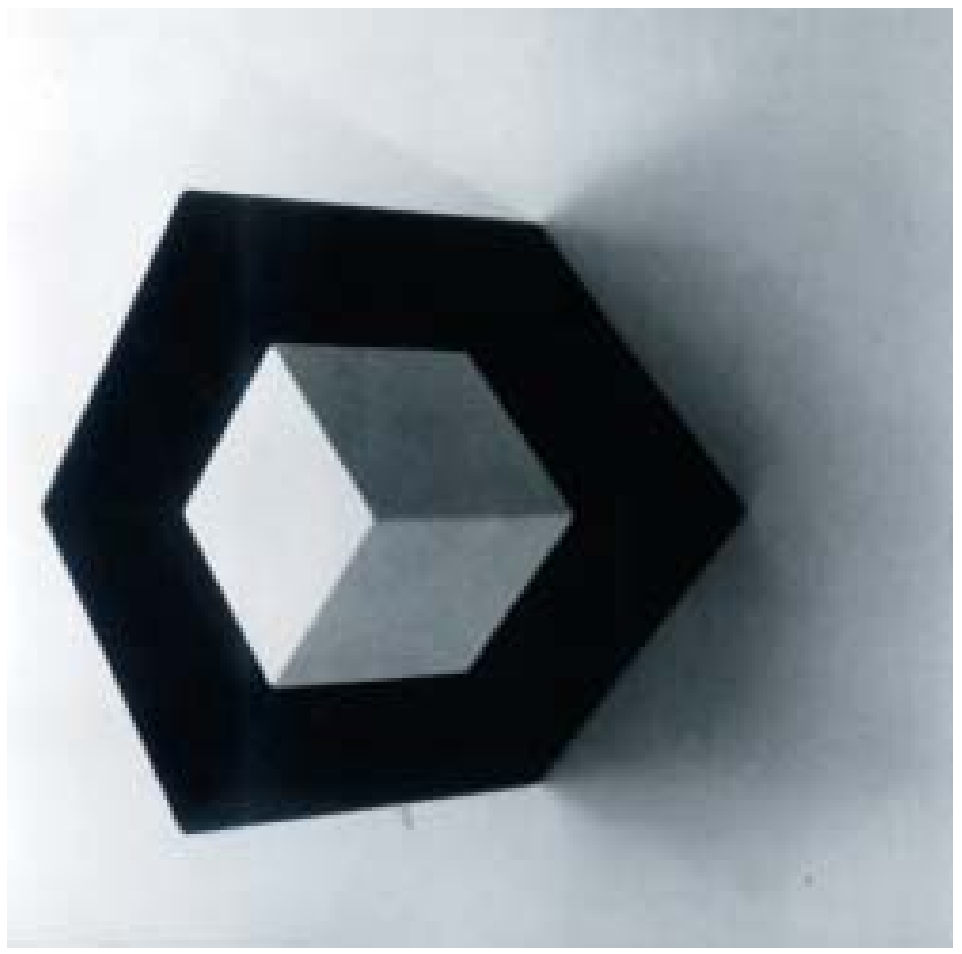

Figura 5 - Objeto ativo de 1962 (vista lateral direita) Fotografia: "Arquivo Pluri e Ativo de Willys de Castro" (IAC)

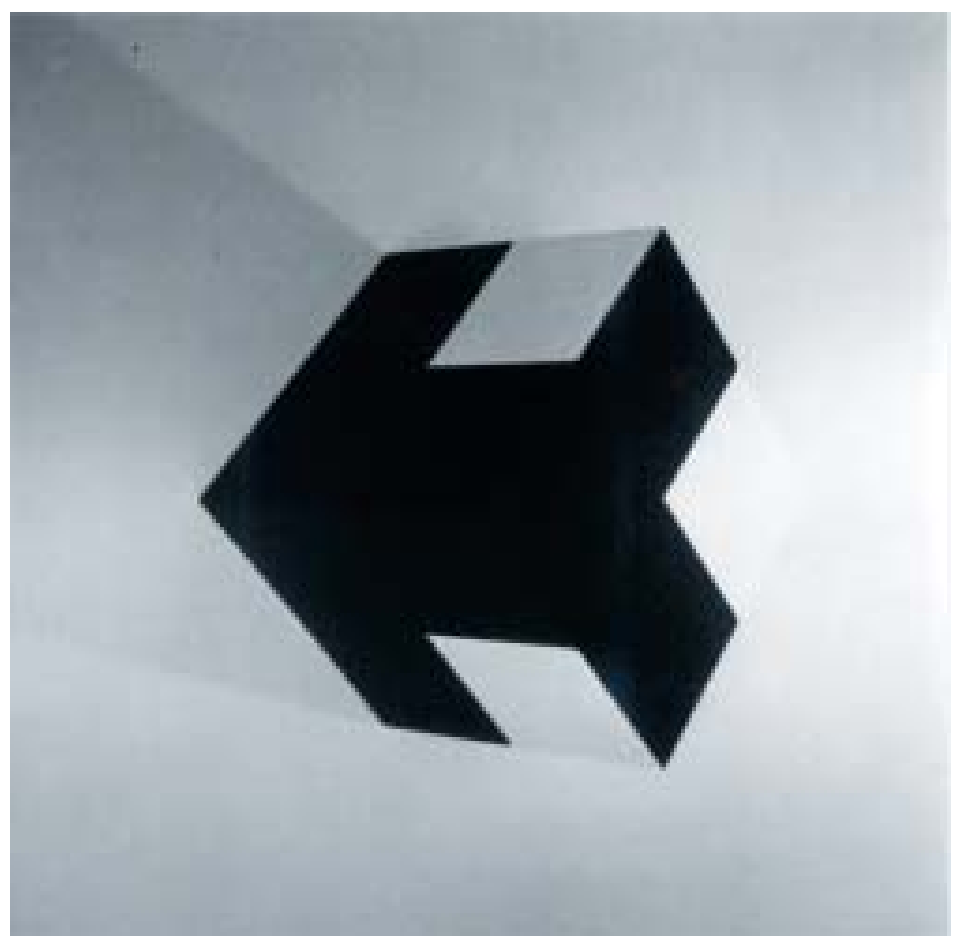

Figura 6 - Objeto ativo de 1962 (vista lateral esquerda) Fotografia: "Arquivo Pluri e Ativo de Willys de Castro" - (IAC) 


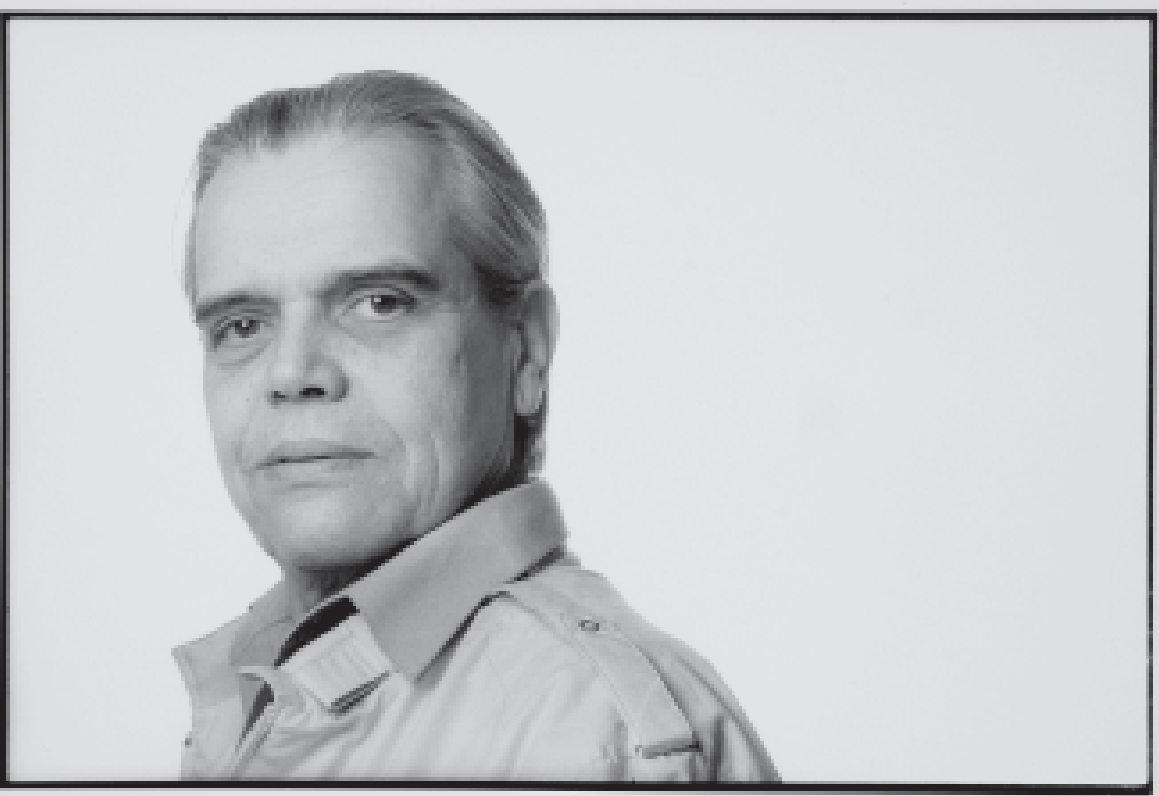

Willys de Castro (1926-1988)

Nos Objetos ativos, Willys de Castro investigou o diálogo entre a pintura e a escultura, delineando suas interfaces. Com o passar do tempo, a pesquisa que começara ativando as características gerais desses meios (a visão pictórica, a tridimensionalidade do objeto etc.) tornou-se mais sutil; assim, na subsérie dos Cubos há o entrelaçamento de dados heterogêneos. Em Objeto ativo de 1962, a perspectiva em diagonal articula uma declaração escultórica (do cubo branco), que é superada por uma ilusão óptica, que, finalmente, desvenda a natureza tridimensional da figura representada. O diálogo é desenvolvido com nuanças cada vez maiores - nuanças essas que nunca sucumbem à indiferença categorial. Isso porque a unidade desses trabalhos reside no modo como convergem para o "paradigma da perspectiva" (cf. Damisch, 1987, p.14 e 40-4), com a finalidade de, a partir daí, declinarem as versões correlativas de pintura e escultura.

Em 1961, Willys de Castro escreveu um pequeno texto sobre os Objetos ativos. Para concluir nosso artigo, gostaríamos de recuperar a espontaneidade própria do seu discurso. Segundo o artista,

A nova obra não é estanque, ela translada os seus significados para o espaço circundante estabelecendo topicamente novas relações e concordâncias. Pois, sem recorrer às referências exteriores, ela coleta de si mesmo os dados necessários à sua comunicação, retirando-os parte do real e parte do virtual. Tal obra - realizada com o espaço e seu acontecimento - ao penetrar no mundo, perturba-o e, pelo seu surgimento, deflagra uma torrente de fenômenos perceptivos e significantes, portadores de novas revelações, até então inéditas nêsse mesmo espaço. Esse novo objeto, investido de tal atividade, torna-se um 
inteiro caracterizado pela sua autonomia e unicidade, e porisso, altamente diferenciado das obras convencionais, contendo eventos dentro do seu próprio tempo - iniciados, transcorridos, findados, reiniciados, etc., e ali demonstrados clara, fluente e indefinidamente - êle inaugura-se no mundo como um instrumento de contar a si próprio. A êste ponto íntegro, emissor de formas auto-expressivas significantes, colocado dentro do mundo sensível, denominamos, pois, de objeto ativo. (Castro, 1961, p.50)

\section{Notas}

1 Este artigo baseia-se num capítulo da minha dissertação de Ph.D em História da Arte, apresentada à Universidade do Texas em Austin (UT). Agradeço aos professores Jacqueline Barnitz, Richard Shiff, Linda Henderson, John Clark e Ana Maria Mauad (UFF) o apoio à realização deste trabalho. Meus estudos foram financiados pela UT, através do Departamento de História da Arte e do Instituto de Estudos Latino-Americanos Lozano Long (LLILAS), pelo CNPq e pela UFF.

2 Neste artigo, analisamos a segunda versão de Objeto ativo de 1959. A primeira tem dimensões reduzidas, medindo 35 X 70 X $0,5 \mathrm{~cm}$. É possível que Willys de Castro tenha refeito esse trabalho para exibi-lo durante a II Exposição Neoconcreta. Sobre essa mostra, ver "II Exposição Neoconcreta: Balanço do Movimento Neoconcreto", Jornal do Brasil, Rio de Janeiro, 26.11.1960, autor anônimo.

3 Agradeço a Marilúcia Bottallo, organizadora do "Arquivo Pluri e Ativo de Willys de Castro", a Raquel Arnauld e a Lu Rodrigues do Instituto de Arte Contemporânea (IAC), a João da Cruz Vicente de Azevedo do Museu de Arte de São Paulo (MASP) e a Célia Euvaldo da Editora CosacNaify, assim como aos fotógrafos das obras do artista, a cortesia de ceder as imagens veiculadas neste artigo.

4 Sobre a lei da "Clausura" ou "Prenhez da forma", ver Pedrosa (1979, p.27-9).

5 Para essa denominação, aceitamos uma sugestão do jornalista Alexandre Martins (1988): "Em 1959 [Willys de Castro] trocou uma pintura baseada no jogo de formas opostas, positivo-negativo, pela construção de objetos, que ele batizou de 'objetos ativos"”.

$6 \mathrm{O}$ artista empregou o motivo positivo-negativo antes do movimento Neoconcreto. As pinturas Conjugações de tensões e pintura 174 - Ritmos coplanares, ambas realizadas em 1956, evidenciam essa linha de pesquisa. Sobre esses trabalhos, ver Castro (1994). Agradeço a Sylvio Nery da Fonseca a cortesia de ceder uma cópia desse catálogo.

7 Ver Saussure (1992, p.718-19). Obviamente, o texto de Saussure foi adaptado, pois ele define o significante como "imagem sonora".

8 Em prol da clareza, nosso argumento foi simplificado. Poderíamos considerar a formação de outro motivo positivo-negativo, posto que a seção amarela - que segmenta a linha azul da superfície frontal - poderia ser projetada ortogonalmente, totalizando a lateral.

$9 \mathrm{Na}$ medida em que a poesia neoconcreta considerava o significado das palavras juntamente com seu registro gráfico, os Objetos ativos apresentam um paralelo com essa produção. Sobre a poesia neoconcreta, ver Jardim (1960).

10 De acordo com Irving Sandler (1970, p.190): "Cada uma das abstrações [de Barnett Newman] é um campo apreendido na sua imediaticidade e completude. As faixas 
verticais dentro dela, embora sugiram imagens, não são percebidas como coisas, separadas de um fundo, avançando ou recedendo. Antes, elas são acentos que energizam a área contínua ao criar escala, ao mesmo tempo fazendo que ela apareça uma extensão vasta enquanto a proíbe de tornar-se amorfa e inerte". É importante ressaltar que Barnett Newman também realizou algumas esculturas que apresentam uma verticalidade bastante acentuada.

11 Em Objeto ativo de 1960, a anamorfose é sugerida esquematicamente. Assim, quando afirmamos que Willys de Castro baseou-se nessa técnica, referimo-nos ao fato de que o trabalho - quando visto num determinada ângulo que produz o ilusão do entalhe assume um caráter gráfico, tal como se o objeto tivesse sido desenhado em perspectiva sobre um plano de projeção inclinado. Sobre a perspectiva, ver Panofsky (1983).

12 O "Manifesto da Arte Concreta" definiu os elementos da pintura assim: "O quadro deve ser inteiramente construído com elementos puramente plásticos, isto é, planos e cores. Um elemento pictural só significa a 'si próprio' e, conseqüentemente, o quadro não tem outra significação que 'ele mesmo'” (Van Doesburg, 1977, p.42).

13 É importante sublinhar que o signo de escorço que Picasso inscreveu em suas colagens também produz um efeito ilusório, pois as dimensões contrastantes $\operatorname{dos} f$ fazem alusão à diminuição perceptiva dos objetos quando se afastam do observador.

14 Em última instância, a sugestão do entalhe em Objeto ativo de 1960 baseia-se nas técnicas do desenho - que recorta os quadrados das suas superfícies originárias - e da ilusão óptica - que é produzida quando esses recortes convergem numa figura imaginária. Enquanto a escultura emprega cada uma dessas técnicas isoladamente, a pintura conjuga-as na mesma operação.

15 Segundo o crítico: "Willys criou algumas de suas obras mais conhecidas, os objetos ativos, nem esculturas nem pinturas (talvez 'pinturas tridimensionais') em que os vértices da estrutura em madeira eram o foco da atenção".

16 De acordo com Leon Battista Alberti (apud Wittkower, 2001, p.78): "Aos que trabalham com cera ou gesso, acrescentam ou subtraem material, nós os chamaremos modeladores, enquanto que os artistas que apenas subtraem, trazendo à luz a figura humana potencialmente oculta no bloco de mármore, são por nós chamados escultores”. As informações contidas nesse parágrafo são provenientes do mesmo livro.

17 Nesse texto, Gullar descreveu o percepção dos Objetos ativos de forma sintética, enfatizando o momento final.

18 Além dos trabalhos estudados neste artigo, o inventário dos Objetos ativos incluiria mais dois formatos: o primeiro apresenta o sarrafo de madeira pendurado horizontalmente na parede; o segundo exibe dois sarrafos verticais, posicionados em paralelo. Os padrões visuais que Willys de Castro desenvolveu nesses objetos são bastante variados, carecendo, portanto, de um estudo detalhado.

19 Estamos analisando o trabalho a partir de um espectador que segue da direita para a esquerda.

20 Trata-se do fenômeno de reversão espacial que resulta do contorno simétrico dos objetos. Sobre a "Propriedade dos contornos", ver Pedrosa (1979, p.31-3).

21 Com efeito, apenas o quadrado da direita - que está posicionado sobre a face frontal do objeto - é um dos elementos do cubo branco. 
Referências bibliográficas

CASTRO, W. de. Objeto ativo. Habitat, n.64, p.50, 1961.

Willys de Castro, obras de 1954-1961. São Paulo: Sylvio Nery da Fonseca Escritório de Arte, 1994.

DAMISCH, H. L'origine da la perspective. Paris: Flammarion, 1987.

DERRIDA, J. Structure, Sign, and Play in the Discourse of the Human Sciences. In: ADAMS, H. Critical Theory since Plato. Orlando: Harcourt Jovanovitch College Publishers, 1992. p.1117-26.

GULLAR, F. Diversificação da experiência neoconcreta. Jornal do Brasil, Rio de Janeiro, 4.12.1960.

JARDIM, R. Não-objeto: onde fala o infinito. Jornal do Brasil, Rio de Janeiro, 4.12.1960

KEMP, M. The Science of Art, Optical Themes in Western Art from Bunelleschi to Seurat. New Haven: Yale University Press, 1990.

KRAUSS, R. The Originality of the Avant-Garde and other Modernist Myths. Cambridge: The MIT Press, 1986.

MARTINS, A. Menos um construtivo na arte. Jornal do Brasil, Rio de Janeiro, 7.6.1988.

PANOFSKY, E. La perspectiva como forma simbolica. Barcelona: Tusquets Editores, 1983.

PEDROSA, M. Arte, forma e personalidade. São Paulo: Kairós, 1979.

ROELS, R. Um artista dedicado a refinar cada vez mais o olhar. Jornal do Brasil, Rio de Janeiro, 6.6.1988.

SANDLER, I. The Triumph of American Painting, a History of Abstract Expressionism. New York; Washington: Praeger Publishers, 1970.

SAUSSURE, F. de. Course in General Linguistics. In: ADAMS, H. Critical Theory since Plato. Orlando: Harcourt Jovanovitch College Publishers, 1992 p.718-19.

VAN DOESBURG, T. Manifesto da Arte Concreta. In: Projeto Construtivo Brasileiro na Arte - 1950-1960. Rio de Janeiro; São Paulo: MEC/Funarte/MAM-RJ/Secretaria de Cultura e Tecnologia de São Paulo/ Pinacoteca do Estado de São Paulo, 1977.

WITTKOWER, R. Escultura. São Paulo: Martins Fontes, 2001.

RESUMO - WILLYS DE CASTRO desenvolveu os Objetos ativos (1959-1962) durante o período neoconcreto. A partir da lingüística de Ferdinand de Saussure e do conceito de "desconstrução" de Jacques Derrida, este artigo defende que a originalidade dessa série de objetos encontra-se na inscrição de "signos". Assim, a análise visual e semântica da descoberta do artista - tais como o "motivo positivo-negativo" e a ênfase na tridimensionalidade do suporte, realizadas em Soma entre planos I (1959), Objeto ativo de 1959, Objeto ativo de 1960 e Objeto ativo de 1962 - demonstra que esses signos representam mudanças sucessivas de registros pictóricos e escultóricos. Concluímos que a unidade desses trabalhos reside na convergência para o "paradigma da perspectiva", para declinarem as versões correlativas de pintura e escultura.

PALAVRas-CHaVE: Willys de Castro, Objetos ativos, Análise visual e semântica, Signo, Desconstrução. 
ABSTRACT - WILLYS DE CASTRO has developed the Objetos ativos (1959-1962) during the neoconcrete phase. In accordance with Ferdinand de Saussure's linguistics and Jacques Derrida's concept of "deconstruction", this article supports the idea that the originality of this series of objects is based on the inscription of "signs". Thus, the visual and semantic analysis of the artist's discoveries - such as the "positive-negative motif" and the emphasis on the tridimensionality of the support, achieved in Soma entre planos I (1959), Objeto ativo de 1959, Objeto ativo de 1960 and Objeto ativo de 1962 - shows that these signs represent consecutive changes of pictorial and sculptural readings. We conclude that the unity of these works is found in the convergence to the "paradigm of perspective" to decline the correlative versions of painting and sculpture.

KErwords: Willys de Castro, Objetos ativos, Visual e semantic analysis, Sign, Deconstruction.

Renato Rodrigues da Silva é professor adjunto do Departamento de Arte da Universidade Federal Fluminense (UFF); Ph.D em História da Arte pela Universidade do Texas em Austin, EUA. Autor de A fotografia moderna no Brasil (CosacNaify, 2004) e de diversos artigos sobre arte moderna e contemporânea, nos quais enfoca os trabalhos de Hélio Oiticica, Ricardo Basbaum e Richard Serra. @ - rsilva@vm.uff.br

Recebido em 5.2.2005 e aceito em 4.4.2005. 